\title{
Chemical inhibition of barnacle larval settlement by the brown alga Fucus vesiculosus
}

\author{
Elisabet Brock*, Göran M. Nylund, Henrik Pavia
}

Department of Marine Ecology, Göteborg University, Tjärnö Marine Biological Laboratory, 45296 Strömstad, Sweden

\begin{abstract}
The possible importance of larval settlement inhibition by Fucus vesiculosus in explaining the low abundance of the barnacle Balanus improvisus on algal fronds compared to adjacent rock was investigated by a combination of field and laboratory studies. A field survey showed that the abundance of adult barnacles was significantly lower on F. vesiculosus than on rocks and settlement preference experiments strongly suggested that settlement avoidance for algal fronds during the natural settlement season was chemically mediated. By using a multi-step approach, whereby both exuded and surface associated metabolites were tested on larval settlement, we further investigated the possible existence of chemical antifouling processes in F. vesiculosus. For exuded metabolites, seawater was conditioned for 1 and $3 \mathrm{~h}$ with both submerged and desiccated algae. Surface extracts at natural concentrations and seawater conditioned with submerged algae had no significant effect on larval settlement, although there was a tendency for reduced settlement in the $3 \mathrm{~h}$ samples. Seawater conditioned with desiccated algae consistently inhibited settlement and chemical analyses showed that the mean phlorotannin level in the water was $31.5 \mu \mathrm{g} \mathrm{ml}^{-1}$, which is ca. $30 \times$ higher than concentrations previously shown to inhibit barnacle settlement. Seawater conditioned with submerged algae had a mean phlorotannin content of $0.85 \mu \mathrm{g} \mathrm{ml}^{-1}$ and in samples conditioned for $3 \mathrm{~h}$ there was a strong and significant negative relationship between phlorotannin concentration and larval settlement, suggesting that the phlorotannin concentration varied around a level inhibitory to barnacle settlement. Altogether, the results from the laboratory experiments strongly suggested that the low larval preference for algae was caused by exudation of waterborne metabolites, primarily phlorotannins. Finally, field measurements showed that phlorotannins exuded from F. vesiculosus can under natural conditions reach concentrations inhibitory to settlement of barnacle larvae.
\end{abstract}

KEY WORDS: Fucus vesiculosus $\cdot$ Phlorotannins $\cdot$ Chemical defence $\cdot$ Fouling $\cdot$ Barnacles $\cdot$ Balanus improvisus $\cdot$ Exudation $\cdot$ Desiccation

Resale or republication not permitted without written consent of the publisher

\section{INTRODUCTION}

The limiting factor for recruitment of sessile marine organisms on intertidal rocky shores can often be a free surface to which they may attach (Wahl 1989, Richmond \& Seed 1991). As a consequence, epibiosis (i.e. organisms colonising the surface of other organisms in a non-mutualistic way) is a widespread phenomenon in such environments. In many temperate areas, dense stands of large, canopy-forming seaweeds provide a major substratum for recruitment of marine epibionts (Jennings \& Steinberg 1997, Wikström \& Kautsky 2004; see also Wahl \& Mark 1999 and associated supplementary Internet files available at: www.int-res.com/journals/meps/supplementarymaterial/\#2002). Fouling organisms can affect the growth and survival of algal hosts (see review by de Nys \& Steinberg 1999) and should therefore select for defence strategies that reduce the recruitment of foulers on the surface of potential hosts. Such strategies include mechanical and physical defences, as well as the production of chemical substances that inhibit settlement of fouling organisms (reviewed by Davis et al. 1989, Wahl 1989, Pawlik 1992, de Nys \& Steinberg 1999, Steinberg et al. 2001). Many studies have demonstrated that seaweeds contain metabolites 
that can inhibit the settlement of fouling organisms (see literature cited by de Nys \& Steinberg 1999, Nylund \& Pavia 2005). However, the vast majority of these studies have been conducted outside of an ecological context, i.e. they have not explicitly aimed to explain the natural distribution patterns of fouling organisms, they have not examined settlement behaviour on algal surfaces compared to other naturally available substrata, and they have not determined ecologically relevant concentrations of the inhibiting metabolites (but see Schmitt et al. 1995, Steinberg et al. 2001, Wikström \& Pavia 2004, Nylund et al. 2005 for exceptions).

Several species of the order Fucales are dominating, canopy-forming macroalgae in the intertidal zone of sheltered and semi-exposed rocky shores of the North Atlantic. The bladder wrack Fucus vesiculosus forms a conspicuous belt in the middle of many North Atlantic intertidal shores, and it is the host for a range of epibiotic sessile taxa, such as hydroids (e.g. Clava multicornis), crustaceans (e.g. Balanus improvisus), bryozoans (e.g. Electra pilosa and Membranipora membranacea) and macro algal epiphytes (e.g. Elachista fucicola and Pilayella littoralis, Ceramium sp.) (Hansson 1998, Wikström \& Kautsky 2004). Fouling organisms colonizing $F$. vesiculosus have the potential to significantly decrease the growth of their host, which should therefore select for increased resistance to fouling (Honkanen \& Jormalainen 2005). However, little is known about natural defence mechanisms against fouling in $F$. vesiculosus and other fucoids. Many fucoid species contain high levels (3 to $15 \%$ DW) of polyphenolic metabolites called phlorotannins, which are known to exude into the water, with a possible role as fouling deterrents (Conover \& Sieburth 1966, Ragan \& Glombitza 1986, Lau \& Qian 2000; but see also Jennings \& Steinberg 1994). In a previous study with laboratory assays, it was shown that phlorotannins extracted from $F$. vesiculosus significantly inhibited settlement of larvae from the barnacle Balanus improvisus at concentrations of 0.1 to $1 \mu \mathrm{g} \mathrm{ml}^{-1}$. Furthermore, it was found that settlement of $B$. improvisus larvae was significantly lower on $F$. vesiculosus fronds in comparison to a less abundant congeneric alga, as well as to plexiglass control panels (Wikström \& Pavia 2004). These findings suggest that $F$. vesiculosus can reduce its epibiotic load through chemical inhibition of larval settlement. However, the suggestion remains speculative as long as it has not be shown that exuded phlorotannins in the water surrounding $F$. vesiculosus can reach concentrations sufficient to inhibit larval recruitment onto the surface of the alga.

We investigated the possible importance of larval settlement inhibition by Fucus vesiculosus in explain- ing the low abundance of the barnacle Balanus improvisus on algal fronds, compared to bare rocks. Bare rock and fucoids are commonly the 2 dominating substrata available for the settlement of sessile invertebrate larvae on many mid-intertidal shores in the North Atlantic, including the Swedish west coast. The natural distribution of $B$. improvisus on $F$. vesiculosus and adjacent rocks was determined in a field study at 3 different sites. To test the hypothesis that the observed low abundance of barnacles on $F$. vesiculosus compared to rocks could be a result of the settlement behaviour of barnacle larvae, we conducted settlement preference experiments, where barnacle larvae were given a choice between rocks and algal fronds. The experiments were carried out on 2 occasions, before and during the natural recruitment season. The results from these experiments suggested that the observed settlement preference during the natural settlement season was chemically mediated and therefore further experiments were carried out in order to determine potential chemical antifouling processes in $F$. vesiculosus. This was done through a multi-step approach, where possible occurrence of both surface associated and exuded algal metabolites inhibiting larval settlement was investigated in the laboratory. In order to mimic the effects of natural variation in water levels on the exudation of algal metabolites (Carlson \& Carlson 1984), the inhibitory activity of exudates was tested for previously emerged, as well as submerged, F. vesiculosus plants. Finally, the levels of phlorotannins were measured in seawater samples from natural stands of F. vesiculosus.

\section{MATERIALS AND METHODS}

Study organisms. The study was performed at Tjärnö Marine Biological Laboratory, on the Swedish west coast $\left(58^{\circ} 52^{\prime} \mathrm{N}, 11^{\circ} 09^{\prime} \mathrm{E}\right)$, between 2001 and 2004. In this area, Fucus vesiculosus, a perennial brown alga of the family Fucaceae, is common in the narrow intertidal zone of sheltered and semi-exposed rocky shores. The barnacle Balanus improvisus is also commonly found in this intertidal zone, attached to rocks, seaweeds and artificial surfaces (Barnes \& Barnes 1962, Foster 1987, Berntsson \& Jonsson 2003, Wikström \& Kautsky 2004). On the Swedish west coast it reproduces during the summer and, in their final morph called cyprids, the planktonic larvae settle from late June to October (Berntsson \& Jonsson 2003). It takes 8 to $24 \mathrm{~h}$ for cyprids to metamorphose to fully functional juveniles (Glenner \& Hoeg 1993). The cyprids used for experiments in this study were reared in a laboratory culture, as described by Berntsson et al. (2000). 
Field abundance of Balanus improvisus. A field survey was conducted to determine the abundance of the barnacle Balanus improvisus on Fucus vesiculosus and adjacent rocks. The field survey was conducted within a specified stretch of $5 \mathrm{~m}$, at each of 3 sites at the end of August 2002. At each site, barnacles attached to 10 haphazardly chosen fronds of adult $F$. vesiculosus $(\mathrm{n}=10)$ were counted. The plants were scanned and their surface area was determined with the pictureanalysing software Image J1.32j (Wayne Rasband, National Institutes of Health, Bethesda). The distribution of barnacles on rocks was determined by counting the number of barnacles found within 10 randomly placed frames $(10 \times 7 \mathrm{~cm})$ at the same depth within the sites as for the algal sampling.

Settlement preference experiment on natural surfaces. The settlement preference of cyprids of Balanus improvisus on Fucus vesiculosus or rock was tested in choice experiments in March and September 2002. The same experimental design was used on both occasions. Rocks and plants for the experiment were collected from a locality near the laboratory. One rock and 1 piece of algal frond from different individuals of $F$. vesiculosus were placed together in 12 containers $(\mathrm{n}=$ 12), with through-flowing filtered $(2 \mu \mathrm{m})$ seawater (FSW) at ca. $20^{\circ} \mathrm{C}$. Tissue samples were taken from the algae and immediately frozen at $-70^{\circ} \mathrm{C}$ for later determination of phlorotannin concentrations. The inside of the containers was lined with plankton net (mesh size $140 \mu \mathrm{m})$ to prevent cyprids from settling on the container walls (cf. Berntsson et al. 2000, Wikström \& Pavia 2004). Into each of the 12 containers, 75 newly moulted cyprids were added. The experiment was run for $7 \mathrm{~d}$ at ambient light-dark cycle, after which settled barnacles on rocks and algae were counted under a dissection microscope.

Surface specific extraction and settlement experiment with surface associated metabolites. Surface associated metabolites were extracted by 2 different methods. Firstly, fronds of Fucus vesiculosus were collected and non-polar metabolites were extracted according to the 'dipping technique' (de Nys et al. 1998, Nylund et al. 2007), which allows non-polar surface associated metabolites to be extracted without coextracting the interior of the algal cells. Using a mixture of $6 \%$ dichloromethane (DCM) in hexane, we extracted individual pieces of $F$. vesiculosus $(\mathrm{n}=5)$ for 0 , $30,40,50$ and $60 \mathrm{~s}$ and measured the effect on cell lysis by epifluorescence microscopy at a magnification of 1000× (Olympus BX 51 microscope, fluorescence mirror unit U-MWB2). Extractions were done in glass vials on a vortex. The effect of extraction time was directly assessed following extraction by counting the number of lysed versus intact cells in 5 different fields of view $\left(0.01 \mathrm{~mm}^{2}\right)$ of the tissues from each extraction time.
Based on the effect of extraction time on cell lysis, surface extracts for bioassays were obtained by extracting pieces of algal tissue separately for $40 \mathrm{~s}$ in glass vials containing $10 \mathrm{ml}$ of a $6 \%$ DCM-hexane mixture. In order to use concentrations of surface extracts in bioassays that would correspond to the natural concentration of surface metabolites of Fucus vesiculosus, a surface area/wet weight ratio was calculated for the alga. Twenty-one algal pieces were weighed and photographed and the surface area of the algal pieces was determined with the picture-analyzing software Image J1.32j. Based on the surface area/wet weight ratio, algal pieces of equal surface area and twice the size of the test dishes used in the bioassays $\left(25 \mathrm{~cm}^{2}\right)$ were extracted. Algal pieces with surface areas both 1 and $2 \times$ the area of the test dishes were extracted, since we did not know how well the procedure extracted all non-polar surface associated metabolites. After evaporating the DCM-hexane mixture, the resulting extracts were used in bioassays.

Surface associated metabolites were also extracted according to the 'swabbing technique' (Schmitt et al. 1995). Pieces of algal tissue, with surface areas either 2 or $4 \times$ the area of the test dishes, were laid flat on a paper tissue, and the upper sides were gently rubbed with GF/A filters (Whatman, $\varnothing=25 \mathrm{~mm}$ ). The filters were placed in separate glass vials and extracted in $10 \mathrm{ml}$ methanol overnight. The resulting extracts were filtered through GF/A filters, transferred into new glass vials, evaporated in a Speed-Vac (Heto, Allerød), and used in bioassays the following day. The dipping and swabbing extractions produced several replicate units of surface extracts, with concentrations corresponding to natural and twice the natural concentration. All the extracted pieces of algal tissue were apical fronds from different algal individuals.

Using cyprids of the barnacle Balanus improvisus, we tested the effects of the surface extracts from Fucus vesiculosus on larval settlement. Surface extracts obtained from the dipping and swabbing extractions were re-dissolved in $2 \mathrm{ml}$ hexane and methanol, respectively. The solutions were transferred to Petri dishes (Nunc, $\varnothing=48 \mathrm{~mm}$ ), left to evaporate on a shaking table and immediately used in bioassays. Solvent controls were also prepared by evaporating equal amounts of solvents as for the surface extractions, and by re-dissolving in hexane and methanol as described above. The surface extracts obtained from the dipping and the swabbing extractions were tested in 2 separate assays, using 10 and 6 replicates, respectively. Fifteen newly moulted cyprids were added to test and control dishes, containing $6 \mathrm{ml}$ FSW, which were incubated for $6 \mathrm{~d}$ at room temperature at ambient light-dark cycle. At the end of the test, the percentage of settled larvae was determined. 
Settlement experiment in seawater conditioned with seaweed exudates. Whole plants of adult Fucus vesiculosus, visibly clean from epiphytes, were randomly collected from localities also inhabited by Balanus improvisus. The collection was made in October, towards the end of the recruitment period of the barnacles. F. vesiculosus on the Swedish west coast can naturally be subjected to several days of emersion due to irregular changes in water levels, caused by wind and fluctuations in atmospheric pressure combined with a small tidal range (Johannesson 1989). Fucoids have previously been found to exude watersoluble metabolites more readily after periods of emersion (Carlson \& Carlson 1984). For these reasons, we conditioned seawater with exuded water-soluble metabolites from both submerged algae and algae that had been desiccated for $24 \mathrm{~h}$. Algal fronds for the seawater incubation were cut into pieces, corresponding to ca. $25 \mathrm{~g}$ algal wet weight, and added to plastic jars $(200 \mathrm{ml})$ filled with $175 \mathrm{ml}$ FSW. Only algal parts without visible epiphytes or herbivore damage were used. The amount of algal tissue used in the jars corresponded to the proportion of algal mass per volume of seawater, measured at 5 randomly chosen locations in the littoral zone. In order to avoid any possible leakage of metabolites, the cutting zone was left above water. The algae were left in the jars for 1 and $3 \mathrm{~h}$, and each incubation time was replicated 5 times $(n=5)$. Jars filled with only FSW served as controls. After the incubation, the effects of seawater conditioned with submerged and desiccated algae, were tested on barnacle settlement in separate assays. Water $(10 \mathrm{ml})$ from each jar was added to Petri dishes (Nunc, $\varnothing=48 \mathrm{~mm}$ ), 20 newly moulted cyprids were transferred to each dish and incubated for $3 \mathrm{~d}$ at room temperature, after which the percentage of settled larvae was determined. Water samples were also frozen for later determination of phlorotannin content.

Phlorotannin analyses. Phlorotannin concentrations were measured in algal tissues for the settlement preference experiment on natural surfaces, for surface extracts, for the conditioned FSW used for laboratory settlement assays and for natural seawater from field samples. Algal tissue samples for phlorotannin analyses were ground to a fine powder and extracted in aqueous acetone ( $60 \%$ by volume) on a shaking rack in the dark at $4^{\circ} \mathrm{C}$ for $24 \mathrm{~h}$. After extraction the samples were centrifuged, evaporated in vacuum to a small aqueous volume, filtered to remove precipitated lipophilic material and diluted to a defined volume. Phlorotannins were quantified colorimetrically using the Folin-Ciocalteu method (Van Alstyne 1995). Phloroglucinol (1,3,5-trihydroxybenzene, art. 7069; Merck, Darmstadt) was used as a standard. Surface extracts and conditioned water samples were filtered, diluted to a defined volume, and the levels of phlorotannins were analysed using the Folin-Ciocalteu method as above.

To determine natural levels of phlorotannins in the seawater in algal belts, 2 different methods of sampling were performed. For the first, $10 \mathrm{ml}$ syringes were used to collect 12 random water samples, both from water close to submerged Fucus vesiculosus plants and water close to plants that had just been submerged after $2 \mathrm{~d}$ of natural emersion (desiccation). For the second, 48 samples of $0.1 \mathrm{ml}$ were taken close to the thalli of naturally desiccated plants just as they had been immersed. This was carried out in order to reduce dilution effects during sampling, and thereby to obtain a better estimate of phlorotannin levels in the thin water layer surrounding the algal thalli at a spatial scale relevant to potential larval settlers. Under both protocols, seawater $2 \mathrm{~m}$ away from the algal zone was also sampled to provide controls for background concentration. All samples were subsequently analysed for phlorotannins using the Folin-Ciocalteu method.

Statistical analyses. Data from the field survey of the abundance of barnacles on Fucus vesiculosus and adjacent rocks, and from the settlement assays and phlorotannin measurements in the experiment with conditioned seawater, were analysed by 2-factor analyses of variance (ANOVA). The results of the settlement preference experiment were analysed with paired $t$-tests, and 1-way ANOVA was used to analyse data on the effect of extraction time on cell lysis, the settlement tests with surface extracts and the natural concentrations of phlorotannins in seawater. Post hoc comparisons were made using Student-NewmanKeuls test (SNK-test) where required (Underwood 1997). Prior to ANOVA, homogeneity of variance for all obtained data was tested with Cochran's test and the data transformed when required, in order to fulfil the requirement of homogenous variance prior to statistical analyses (Underwood 1997). The data from the survey of barnacle abundance, and the field measurement of phlorotannin concentrations were log-transformed. Data from the test on the effect of extraction time on cell lysis were arcsin transformed.

\section{RESULTS}

\section{Field abundance of Balanus improvisus}

The abundance of adult barnacles of Balanus improvisus in the field was significantly higher on rocks than on algae at all 3 investigated sites (2-way ANOVA: $F_{2,54}=8.86, \mathrm{p}=0.0005$; followed by SNK-test on the interaction: $\alpha=0.05$ ) (Fig. 1 ). 


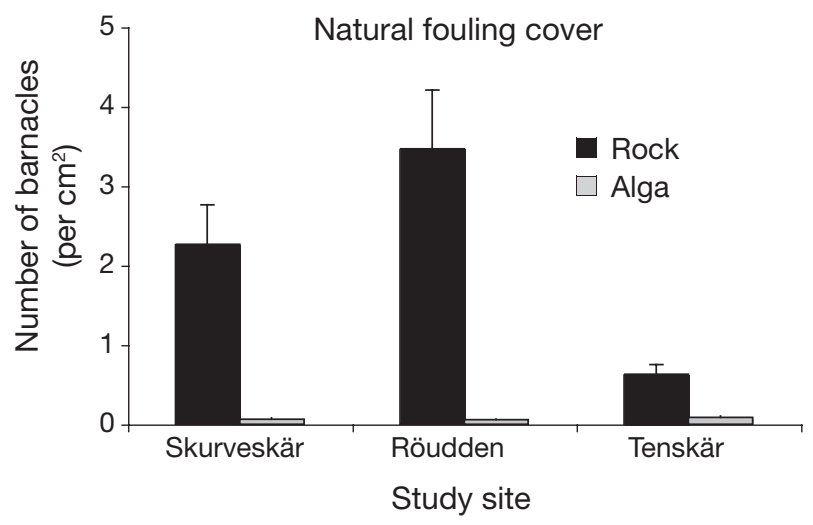

Fig. 1. Balanus improvisus. Abundance of barnacles on rock and alga at 3 study sites (mean $+\mathrm{SE}, \mathrm{n}=10$ )

\section{Settlement preference experiment on natural surfaces}

Cyprids of Balanus improvisus preferred to settle on rocks compared to algae in the experiment conducted in September (paired $t$-test, $t=2.78, \mathrm{p}=0.018$; Fig. 2). In contrast there was no statistically significant difference between settlement on rocks and algae in March (paired $t$-test: $t=-0.52, \mathrm{p}=0.62$; Fig. 2). The average number of settled cyprids on both algae and rocks was 6.6 and 7.3 for the March and September experiment respectively. No larvae had settled on the plankton nets. Algal tissue samples had significantly higher levels of phlorotannins in September than in March (1-way ANOVA: $\left.F_{1,16}=79.69, \mathrm{p}<0.0001\right)$ : means $\pm \mathrm{SE}$ $4.54 \pm 0.30$ and $1.58 \pm 0.15 \% \mathrm{DW}$, respectively.

\section{Surface specific extraction and settlement experiment with surface associated metabolites}

Dipping pieces of Fucus vesiculosus tissue in a mixture of $6 \% \mathrm{DCM}$ in hexane for different time periods resulted in a significant effect of immersion time on lysis of surface cells (1-way ANOVA: $F_{4,20}=20.71$, p < 0.0001) (Fig. 3). No significant cell lysis occurred between 0 to $50 \mathrm{~s}$, but it increased significantly from a mean of $4.6 \%$ at $50 \mathrm{~s}$ to a mean of $33.0 \%$ when tissue was immersed for $60 \mathrm{~s}$ (SNK-test: $\alpha=0.05$ ).

The surface extracts obtained from the dipping and swabbing extractions had no effect on cyprid settlement (dipping: 1 -way ANOVA, $F_{2,27}=2.39, \mathrm{p}=0.11$; swabbing: 1-factor ANOVA, $F_{2,15}=0.94, \mathrm{p}=0.41$ ) (Fig. 4). Phlorotannins were not detectable in the surface extracts except for 2 replicates of the swabbing samples. These 2 replicates had a mean concentration ( $\pm \mathrm{SD}$ ) of $0.10 \pm 0.016 \mu \mathrm{g} \mathrm{cm}^{-2}$ algal surface, which corresponds to $0.41 \pm 0.067 \mu \mathrm{g} \mathrm{ml}^{-1}$ in the Petri dishes used in the settlement assays.

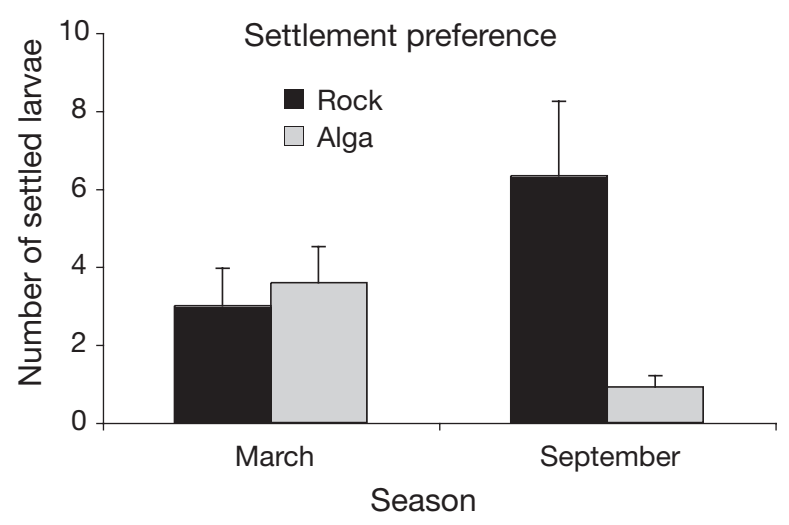

Fig. 2. Balanus improvisus. Settled larvae in settlement preference experiment on rock and alga (mean $+\mathrm{SE}, \mathrm{n}=12$ )

\section{Settlement experiment in seawater conditioned with seaweed exudates}

Larval settlement was significantly inhibited by seawater conditioned with desiccated algae (2-way ANOVA: $F_{2,24}=4.55, \mathrm{p}=0.021$; followed by SNK-test on the interaction: $\alpha=0.05$ ) (Fig. 5). For seawater conditioned with submerged plants, no significant effect on settlement could be confirmed through SNK-test, although there was a tendency for reduced settlement in the seawater incubated for $3 \mathrm{~h}$ (Fig. 5). The phlorotannin levels in water from desiccated algae were significantly higher (mean $\pm \mathrm{SD}: 31.50 \pm 30.05 \mu \mathrm{g} \mathrm{ml}^{-1}$ ) than water from submerged (mean \pm SD: $0.85 \pm 0.30 \mu \mathrm{g}$ $\mathrm{ml}^{-1}$ ). No significant difference in phlorotannin concentrations was detected between the 1 and $3 \mathrm{~h}$ incubation time (2-way ANOVA: $F_{1,16}=1.45, \mathrm{p}=0.25$ ). In the seawater incubated for $3 \mathrm{~h}$ with submerged algae,

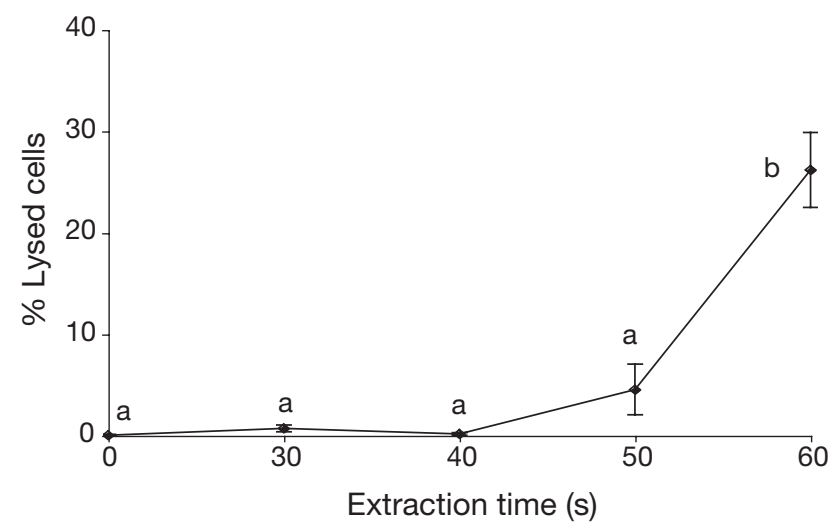

Fig. 3. Fucus vesiculosus. Percentage of lysed surface cells following extraction (immersion) in a mixture of $6 \%$ dichloromethane in hexane for different time periods (mean + $\mathrm{SE}, \mathrm{n}=5$ ). Significant differences indicated by different letters above bars (SNK-test, $\alpha=0.05$ ) 


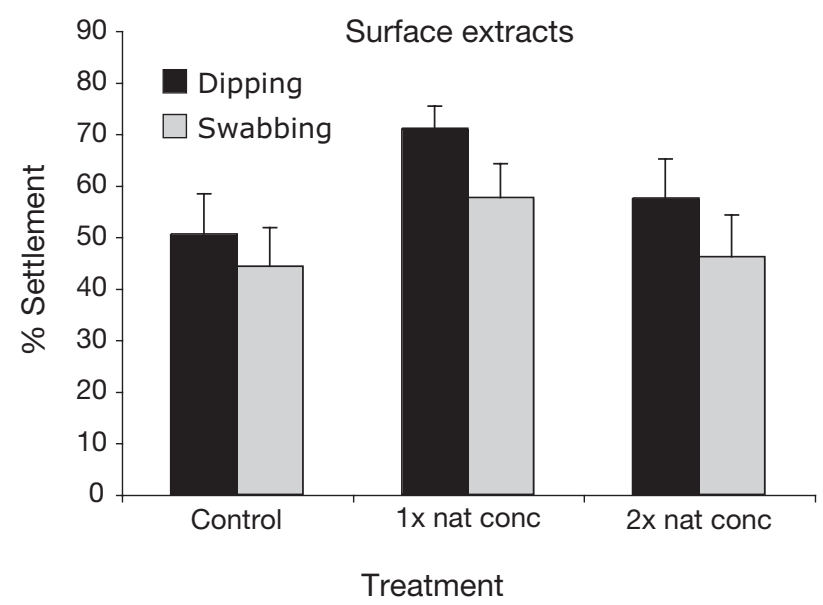

Fig. 4. Balanus improvisus. Effects of surface extracts of Fucus vesiculosus on settlement success (\%); larvae tested against surface extracts obtained from both dipping and swabbing extractions: means $+\mathrm{SE}, \mathrm{n}=10$ (dipping) and 6 (swabbing).

Nat conc: natural concentration

there was a significant negative relationship between settlement success and phlorotannin concentrations (linear regression: $\mathrm{r}^{2}=0.97, \mathrm{k}=-148.3, \mathrm{p}=0.0018$ ). Phlorotannins could not be detected in the seawater controls.

\section{Natural concentrations of phlorotannins in seawater}

For the first sampling protocol (10 $\mathrm{ml}$ samples) in the algal zone, phlorotannin levels close to desiccated algae were $1.97 \pm 0.26 \mu \mathrm{g} \mathrm{ml}^{-1}$ (mean $\pm \mathrm{SE}$ ). This was

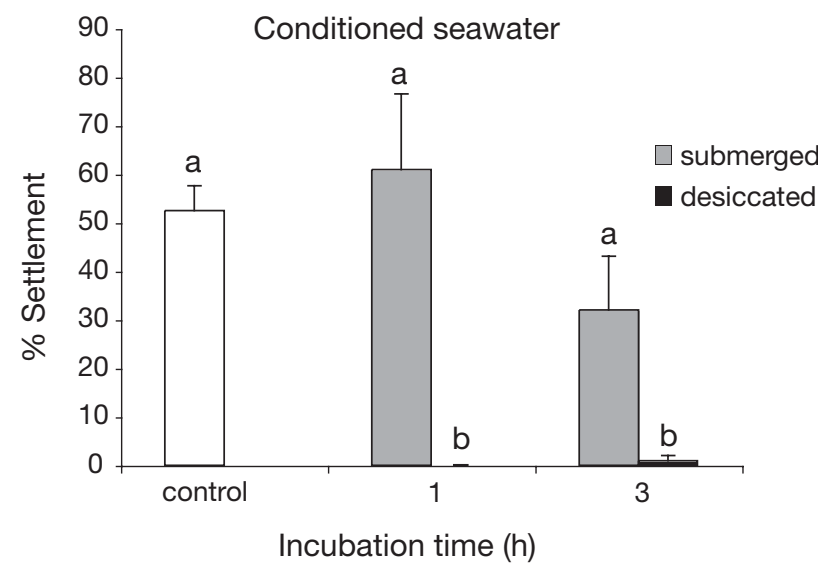

Fig. 5. Balanus improvisus. Percentage of settled larvae in water conditioned with submerged and desiccated Fucus vesiculosus plants; control is filtered seawater (means $+\mathrm{SE}, \mathrm{n}$ $=5$ ). Significant differences indicated by different letters above bars (SNK-test, $\alpha=0.05$ )

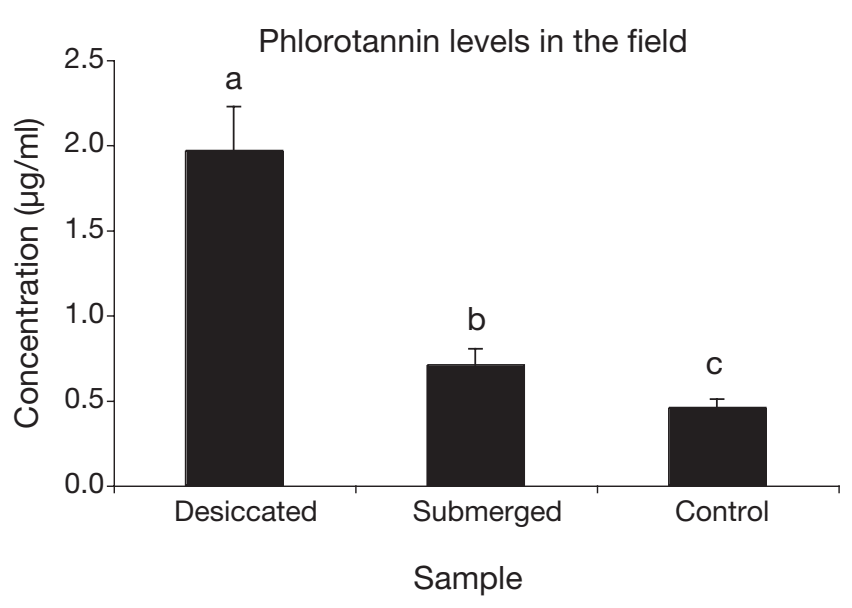

Fig. 6. Fucus vesiculosus. Levels of phlorotannins $\left(\mu \mathrm{g} \mathrm{ml}^{-1}\right)$ in seawater around alga in the field; seawater collected close to both desiccated and submerged algae and $2 \mathrm{~m}$ away from algal belt (control) (mean $+\mathrm{SE}, \mathrm{n}=12$ ). Significant differences indicated by different letters above bars (SNK-test, $\alpha=0.05)$

significantly higher than for water taken close to submerged plants $\left(0.71 \pm 0.093 \mathrm{ug} \mathrm{ml}^{-1}\right)$, and for samples taken in the water $2 \mathrm{~m}$ away from the algal stands $\left(0.46 \pm 0.051 \mu \mathrm{g} \mathrm{ml}^{-1}\right)\left(1\right.$-way ANOVA: $F_{2,33}=47.00, \mathrm{p}<$ 0.0001 followed by SNK-test, $\alpha=0.05$ ) (Fig. 6). For the second sampling protocol, the concentration of phlorotannins in the 48 water samples was $3.44 \pm 3.29 \mathrm{\mu g} \mathrm{ml}^{-1}$ (mean $\pm \mathrm{SD})$.

\section{DISCUSSION}

Many studies have demonstrated that seaweeds contain metabolites which are effective in inhibiting settlement of fouling organisms (see de Nys \& Steinberg 1999, Nylund \& Pavia 2005 for references). However, few studies have demonstrated that the inhibitory activity is ecologically relevant, i.e. that the algal metabolites are present at the algal surface, or in the surrounding water, at concentrations that are deterrent to naturally occurring foulers (but see Schmitt et al. 1995, Steinberg et al. 2001, Nylund et al. 2005, Dworjanyn et al. 2006, Paul et al. 2006). In this study, we combined field and laboratory work to investigate the possible importance of larval settlement inhibition by Fucus vesiculosus, in explaining the low abundance of the barnacle Balanus improvisus on algal fronds, compared to adjacent rocky substrata. We started by determining the natural distribution of $B$. improvisus on $F$. vesiculosus and it was observed that the abundance of adult barnacles was significantly higher on rocks than on algae at all 3 investigated sites. Observation of spatial and temporal variation in distribution 
and abundance of organisms through an objective, random sampling procedure is an eligible starting point, although commonly lacking in antifouling studies, from which logical explanatory models and hypotheses about ecological mechanisms and causal relationship arise (Underwood \& Denley 1984). In general, the natural distribution of fouling organisms reflects events working on both settlement and post-settlement stages of colonizing propagules. In this study, we focused on the potential importance of settlement processes in explaining the observed abundance of $B$. improvisus on $F$, vesiculosus compared to rocks. It should be pointed out that experimental support for any explanatory model and predictive hypothesis focusing on settlement processes will not exclude the possibility that post-settlement processes are also important in determining abundance (cf. Wikström \& Pavia 2004). If, however, experiments testing hypotheses about settlement processes provide no support for the underlying explanatory model, the implication will be that post-settlement events, such as predation or detachment, are the determinant processes for the distribution pattern of fouling organisms.

The settlement preference experiments where Balanus improvisus larvae were offered a choice between rock and algal surfaces provided support for the notion that settlement processes are important in explaining the observed distribution pattern of adult barnacles. The cyprids were significantly deterred from settling on Fucus vesiculosus fronds compared to rock in September, which is within the natural recruitment season of B. improvisus in Swedish waters (Berntsson \& Jonsson 2003). In contrast, there was no significant settlement preference of the larvae for either rock or algal surfaces in the March experiment. This difference strongly suggests that the settlement behaviour of the larvae was chemically mediated in the September experiment, since the physical surface properties (e.g. texture) are most likely to have been similar between seasons. In theory, the difference in settlement behaviour between the 2 occasions could also be due to seasonal physiological differences for the cyprids. However, we found that possibility most unlikely, since we have never observed any signs of seasonal variation in the discriminatory behaviour of cyprids despite years of experience of laboratory settlement experiments with reared B. improvisus larvae.

Settlement experiments with intact organisms, aimed at investigating whether potential hosts deter settlement of fouling organisms per se, are rarely included in studies on chemical inhibition of fouling by potential seaweed or invertebrate hosts. The vast majority of studies on chemical inhibition of fouling have instead been directly and solely focused on inhibitory effects of crude extracts or purified natural products in settlement assays. This contrasts strongly with studies on the chemical ecology of plant-herbivore interactions, where the prevalent procedure is to start with feeding tests using intact plant tissue, to proceed with homogenised tissue in order to separate effects of texture (mechanical resistance) from chemical deterrence and then to test extracted compounds in artificial food when homogenised tissue feeding indicates chemical deterrence (see Hay et al. 1998). We cannot see any good reasons why such a logical stepwise procedure should not be more commonly used also in ecological antifouling studies.

Further investigation of a possible chemical antifouling mechanism in Fucus vesiculosus was carried out using a multi-step approach whereby both surface associated and exuded metabolites were tested for their effects on cyprid settlement. The settlement tests showed that surface extracts at natural and twice the natural concentration, as well as seawater conditioned with submerged $F$. vesiculosus fronds, had no significant overall effect on cyprid settlement, although there was a tendency for reduced settlement after $3 \mathrm{~h}$ of incubation with submerged algae. Seawater conditioned with desiccated fronds, on the other hand, inhibited settlement completely and had a mean phlorotannin concentration of $31.5 \mu \mathrm{g} \mathrm{ml}^{-1}$. Given the findings of previous studies on the effects of phlorotannins on barnacle settlement, where significant settlement inhibition occurred at a phlorotannin concentration of ca. $1 \mathrm{\mu g} \mathrm{ml}^{-1}$ (Lau \& Qian 2000, Wikström \& Pavia 2004), it seems most likely that exuded phlorotannins from desiccated $F$. vesiculosus were responsible for the observed inhibitory activity against settlement of cyprids in the seawater conditioned with desiccated algae. Seawater conditioned with brown algae will contain exuded compounds other than phlorotannins, and these compounds could in principle also contribute to the observed inhibition of larval settlement. However, in a previous study on the chemical inhibition of settlement of Balanus improvisus larvae on fucoids, the deterrent activity of crude aqueous extracts from $F$. vesiculosus was directly attributed to the presence of phlorotannins through additional settlement tests with extracts where phlorotannins had been specifically removed with polyvinylpolypyrrolidone (PVPP) (Wikström \& Pavia 2004). Since the crude extracts used in the settlement assays of Wikström \& Pavia (2004) also contained all other extractable, water-soluble compounds from $F$. vesiculosus tissue, it is reasonable to assume that the inhibitory effects we observed from the conditioned water in this study were primarily due to the activity of the phlorotannins.

Seawater conditioned with submerged algal fronds had a mean phlorotannin content of $0.85 \mathrm{\mu g} \mathrm{ml}^{-1}$, which is close to the level where previous studies have found 
significant inhibition effects of phlorotannins on barnacle settlement (Lau \& Qian 2000, Wikström \& Pavia 2004). In contrast to these earlier studies with controlled dilution intervals of phlorotannin treatment levels in settlement experiments, the phlorotannin concentration in our experiments with conditioned seawater varied substantially among replicate water samples. In the seawater samples conditioned for $3 \mathrm{~h}$ with submerged algae, there was a tendency for a reduction in settlement of cyprids, although the difference could not be statistically confirmed in the post-hoc test. However, the regression analyses using the replicate water samples in this treatment revealed a strong and significant negative relationship between phlorotannin concentration and larval settlement. This negative relationship suggests that the phlorotannin levels varied around a level inhibitory to barnacle settlement, which would explain why the overall settlement was not statistically different from the control, even though some replicate water samples reduced the settlement by $>80 \%$. Submerged algal fronds were also used in the settlement preference experiments, which showed that cyprids were significantly deterred from settling on Fucus vesiculosus fronds compared to rock in September, most likely as a result of chemical inhibition. In the settlement preference experiment, larvae were allowed to explore the surface of algae where concentrations of exuded metabolites are expected to be at the highest. Exuded polar metabolites in the jars used for the conditioned seawater, however, were most likely strongly diluted compared to the thin boundary layer surrounding the algal fronds, which is the relevant spatial scale for cyprids approaching a potential settlement surface. In spite of this dilution effect, the mean phlorotannin level in the seawater conditioned with submerged algae was close to concentrations that have previously been shown to inhibit larval settlement (Lau \& Qian 2000, Wikström \& Pavia 2004). Altogether, the results from the 2 different settlement experiments with conditioned water, in combination with the complete lack of larval settlement inhibition in the experiments with algal surface extracts, imply that the low larval preference for algal fronds in the laboratory experiment was caused by exudation of waterborne metabolites, primarily phlorotannins.

It is noteworthy that tissue samples from the seaweeds used in the settlement preference experiment had significantly higher phlorotannin levels in September, when larval settlement on algal fronds was deterred, compared to March, when there was no difference in settlement between rocks and algal fronds. Previous studies have found weak (Jennings \& Steinberg 1997) or no (Honkanen \& Jormalainen 2005) relationship between fouling load and tissue phlorotannin content. Correlations between chemical tissue content and fouling load or settlement rates should, however, be interpreted with great caution. Although it may seem reasonable to assume that exudation of phlorotannins into the water column is positively related to phlorotannin tissue content of seaweeds, there are no published data to support this assumption. In a recent study of the antibiotic activity of halogenated compounds in the red algae Asparagopsis armata it was found that release rates of these compounds into the surrounding seawater was not correlated with the levels in the algal tissue (Paul et al. 2006). As long as the relationship between tissue content and exudation rate of phlorotannins has not been rigorously quantified, correlative data between fouling pressure and phlorotannin tissue content are of little explanatory value in ecological antifouling studies. This is obviously true also for our findings of substantial and corresponding differences in tissue phlorotannin contents and settlement inhibition between the March and September experiments.

Phlorotannins are highly water-soluble and should readily dissolve away from the surface of the seaweed producing them (Steinberg et al. 1998). Thus, the effectiveness of phlorotannins as deterrents of fouling organisms depends on their in situ concentrations near the surface of the host. In a previous study, it was shown that natural concentrations of exuded metabolites from the kelp Ecklonia radiata were insufficient to deter settlement of the ecologically relevant fouling species Ulva lactuca (Jennings \& Steinberg 1997). E. radiata is a sublittoral seaweed and, as Jennings \& Steinberg (1997) pointed out, the effectiveness of phlorotannins as antifoulants may be more significant for intertidal seaweeds like Fucus vesiculosus, which grow on sheltered or semi-sheltered shores with lowturbulent water regimes and can exude 'spikes' of high levels of phlorotannins as they undergo cycles of immersion and emersion. These spikes of exuded phlorotannins should be correlated with increased larval transportation to shores due to tidal water movements (see Shanks 1995). The possibility that F. vesiculosus can exude spikes of phlorotannins after periods of emersion is supported by our findings, where seawater conditioned with desiccated fronds had significantly higher levels of phlorotannins than seawater conditioned with submerged fronds. Furthermore, phlorotannin levels were significantly higher in the water surrounding desiccated fronds of natural populations of $F$. vesiculosus than water surrounding submerged fronds. Phlorotannin concentrations in most of the field samples were close to (for submerged algae), or just above (for recently immersed algae) levels that previously have been shown to inhibit barnacle recruitment in laboratory assays (Lau \& Qian 2000, Wikström \& Pavia 2004). It is also important to recog- 
nize that settlement and metamorphosis of cyprids on seaweed fronds will occur in the narrow boundary layer surrounding the algal surface, where the concentration of exuded metabolites is many times higher than in the adjacent water column (see Jennings \& Steinberg 1997 for further discussion). The difference in our results between the 2 field sampling protocols, where we detected higher concentrations of phlorotannin at the algal surface in the $0.1 \mathrm{ml}$ water samples than in the $10 \mathrm{ml}$ samples, which inevitably became more diluted, suggests that the actual concentration of phlorotannins in the boundary layer is higher than we could determine with our sampling technique.

Based on findings from research on seaweeds and marine invertebrates, as well as on ecological and evolutionary theory, it has been suggested that: 'natural antifoulants will primarily be nonpolar secondary metabolites localized within an organism, in a fashion that will enable the metabolites to be released to the surface. Polar metabolites, such as phlorotannins, are likely to be less effective because of the rapid dissolution of such metabolites away from the surface of the producing organism' (Steinberg et al. 2001, p. 366). This seems logical, since the cost of the synthesis of metabolites should ultimately constrain the amounts of antifoulants being produced and restrict the ability of an organism to replace metabolites that are continuously lost from the surface through dissolution (Steinberg et al. 1998). This reasoning has also been supported by some of the earlier studies on antifouling effects of brown algal phlorotannins, where hundreds of micrograms of phlorotannins per millilitre were required to deter fouling organisms (see Jennings \& Steinberg 1997 and references therein). To obtain such high metabolite concentrations in the water surrounding the algal surface would, under most natural conditions, require unrealistic rates of production and exudation of phlorotannins. Accordingly, no studies have demonstrated that such high levels of phlorotannins occur in water samples from natural seaweed stands. However, a few recent studies, including the present, have shown that phlorotannins from brown seaweeds can deter the settlement of invertebrate larvae at a concentration of $1 \mu \mathrm{g} \mathrm{ml}^{-1}$ or even lower (Lau \& Qian 1997, 2000, Wikström \& Pavia 2004). As shown by the results of this study, such concentrations (and probably even higher) can be reached in water surrounding intertidal brown seaweeds, especially after periods of emersion. These findings do not oppose the general notion that most natural antifoulants will be nonpolar metabolites bound to the surface of organisms. Rather, they support the idea that brown algal phlorotannins may be one of few examples of polar metabolites that play an ecologically relevant role as inhibitors of fouling, at least in intertidal seaweeds on sheltered shores.
Acknowledgements. We thank S. Enge and V. Peny for laboratory assistance. This research was supported by the Swedish Research Council through contracts 621-2002-289 and 621-2004-2658 and by MARICE (Marine Chemical Ecology), an interdisciplinary research platform at the Faculty of Sciences, Göteborg University). The foundations of Birgit and Birger Wåhlströms Minnesfond and Kapten Carl Stenholm provided additional financial support.

\section{LITERATURE CITED}

Barnes H, Barnes M (1962) The distribution and general ecology of Balanus balanoides together with some observation on Balanus improvisus in the waters around the coasts of Denmark, southern Sweden and north-east Germany. Acta Univ Lund N F Avd 2. 58(8):1-41

Berntsson KM, Jonsson PR (2003) Temporal and spatial patterns in recruitment and succession of a temperate marine fouling assemblage: a comparison of static panels and boat hulls during the boat season. Biofouling 19:187-195

Berntsson KM, Jonsson PR, Lejhall M, Gatenholm P (2000) Analysis of behavioural rejection of micro-textured surfaces and implications for recruitment by the barnacle Balanus improvisus. J Exp Mar Biol Ecol 251:59-83

Carlson DJ, Carlson ML (1984) Reassessment of exudation by fucoid macroalgae. Limnol Oceanogr 29:1077-1087

Conover JT, Sieburth J (1966) Effect of tannins excreted from Phaeophyta on planktonic animal survival in tide pools. Proc Int Seaweed Symp 5:99-100

Davis A, Targett N, McConnell O, Young C (1989) Epibiosis of marine algae and benthic invertebrates: natural products chemistry and other mechanisms inhibiting settlement and overgrowth. In: Scheuer PJ (ed) Bioorganic marine chemistry, Vol 3. Springer-Verlag, Berlin, p 85-114

de Nys R, Steinberg PD (1999) Role of secondary metabolites from algae and seagrasses in biofouling control. In: Fingerman M, Nagabhushanam R, Thompson MF (eds) Recent advances in marine biotechnology, Vol 3. Science Publishers, Enfield, NH, p 223-244

de Nys R, Dworjanyn SA, Steinberg PD (1998) A new method for determining surface concentrations of marine natural products on seaweeds. Mar Ecol Prog Ser 162:79-87

Dworjanyn SA, de Nys R, Steinberg PD (2006) Chemically mediated antifouling in the red alga Delisea pulchra. Mar Ecol Prog Ser 318:153-163

Foster BA (1987) Barnacle ecology and adaptation. In: Southward AJ (ed) Barnacle biology, crustacean issues 5 . Balkema, Rotterdam, p 113-133

Glenner H, Hoeg JT (1993) scanning electron microscopy of metamorphosis in four species of barnacles (Cirripeda, Thoracica, Balanomorpha). Mar Biol 117:431-439

Hansson HG (1998) Sydskandinaviska marina flercelliga evertebrater. Västra Götaland County Administration Report No 1998: X, Miljöavdelningen, Göteborgs Länstryckeri AB, Göteborg

Hay M, Stachowicz J, Cruz-Rivera E, Bullard S, Deal M, Lindquist N (1998) Bioassays with marine and freshwater macroorganisms. In: Haynes KF, Millar JG (eds) Methods in chemical ecology, Vol 2, Bioassay methods. Kluwer Academic publishers, Boston, MA, p 39-141

Honkanen T, Jormalainen V (2005) Genotypic variation in tolerance and resistance to fouling in the brown alga Fucus vesiculosus. Oecologia 144:196-205

Jennings JG, Steinberg PD (1994) In situ exudation of phlorotannins by the sublittoral kelp Ecklonia radiata Mar Biol 121:349-354 
Jennings JG, Steinberg PD (1997) Phlorotannins versus other factors affecting epiphyte abundance on the kelp Ecklonia radiata. Oecologia 109:461-473

Johannesson K (1989) The bare zone of Swedish rocky shores - why is it there? Oikos 54:77-86

Lau SCK, Qian PY (1997) Phlorotannins and related compounds as larval settlement inhibitors of the tube-building polychaete Hydroides elegans. Mar Ecol Prog Ser 159:219-227

Lau SCK, Qian PY (2000) Inhibitory effect of phenolic compounds and marine bacteria on larval settlement of the barnacle Balanus amphitrite amphitrite Darwin. Biofouling 16:47-58

Nylund GM, Pavia H (2005) Chemical versus mechanical inhibition of fouling in the red alga Dilsea carnosa. Mar Ecol Prog Ser 299:111-121

Nylund GM, Cervin G, Hermansson M, Pavia H (2005) Chemical inhibition of bacterial colonization by the red alga Bonnemaisonia hamifera. Mar Ecol Prog Ser 302:27-36

Nylund GM, Gribben PE, de Nys R, Steinberg PD, Pavia H (2007) Surface chemistry versus whole-cell extracts: antifouling tests with seaweed metabolites. Mar Ecol Prog Ser 329:73-84

Paul NA, de Nys R, Steinberg PD (2006) Chemical defence against bacteria in the red alga Asparagopsis armata: linking structure with function. Mar Ecol Prog Ser 306:87-101

Pawlik JR (1992) Chemical ecology of the settlement of benthic marine invertebrates. Oceanogr Mar Biol 30:273-335

Ragan MA, Glombitza KW (1986) Phlorotannins, brown algal polyphenols. Prog Phycol Res 4:129-241

Richmond MD, Seed R (1991) A review of marine macrofouling communities with a special reference to animal fouling. Biofouling 3:151-168

Schmitt TM, Hay ME, Lindquist N (1995) Constraints on chemically mediated coevolution: multiple functions for seaweed secondary metabolites. Ecology 76:107-123

Editorial responsibility: Howard Browman (Associate Editorin-Chief), Storebø, Norway
Shanks AL (1995) Mechanisms of cross-shelf dispersal of larval invertebrates and fish. In: McEdward L (ed) Ecology of marine invertebrate larvae. CRC Press, Boca Raton, FL, p 323-367

Steinberg PD, de Nys R, Kjelleberg S (1998) Chemical inhibition of epibiota by Australian seaweeds. Biofouling 12: 227-244

Steinberg P, de Nys R, Kjelleberg S (2001) Chemical mediation of surface colonization. In: McClintock, JB, Baker, BJ (eds) Marine chemical ecology. CRC Press, Boca Raton, FL, p 355-387

Underwood AJ (1997) Experiments in ecology: their logical design and interpretation using analysis of variance. Cambridge University Press, Cambridge

Underwood AJ, Denley EJ (1984) Paradigms, explanations and generalizations in models for the structure of intertidal communities on rocky shores. In: Strong DR, Simberloff D, Abele LG, Thistle AB (eds) Ecological communities: conceptual issues and the evidence. Princeton University Press, Princeton, NJ, p 151-180

Van Alstyne KL (1995) Comparison of three methods for quantifying brown algal polyphenolic compounds. J Chem Ecol 21:45-58

Wahl M (1989) Marine epibiosis. I. Fouling and antifouling: some basic aspects. Mar Ecol Prog Ser 58:175-189

Wahl M, Mark O (1999) The predominantly facultative nature of epibiosis: experimental and observational evidence. Mar Ecol Prog Ser 187:59-66

Wikström SA, Kautsky L (2004) Invasion of a habitat-forming seaweed: effects on associated biota. Biol Invasions 6: 141-150

Wikström SA, Pavia H (2004) Chemical settlement inhibition versus post-settlement mortality as an explanation for differential fouling of two congeneric seaweeds. Oecologia 138:223-230

Submitted: May 8, 2006; Accepted: October 10, 2006

Proofs received from author(s): April 13, 2007 